\title{
Immunotherapy with allergen-loaded nanoparticles containing lipopolysaccharide from Brucella ovis
}

Condensed title: Gantrez nanoparticles for immunotherapy

Authors: Sara Gómez ${ }^{1}$, Carlos Gamazo ${ }^{1}$, Beatriz San Roman ${ }^{1}$, Marta Ferrer ${ }^{2}$, Maria Luisa Sanz ${ }^{2}$, Juan M. Irache ${ }^{1 *}$

${ }^{1}$ Adjuvant Unit, Department of Pharmaceutical Technology and Microbiology, University of Navarra, 31080 Pamplona, Spain.

${ }^{2}$ Allergy Department, University Hospital of Navarra, 31080 Pamplona, Spain.

\section{*Corresponding autor:}

Dr. Juan M. Irache

Centro Galénico. University of Navarra

Ap.177, 31080 Pamplona. Spain

Tel: +34 948 425600; Fax: +34948425649

e-mail:jmirache@unav.es 


\section{Abstract}

Background: Specific immunotherapy implies certain drawbacks which could be minimized by the use of good adjuvants, capable of amplifying the appropriate immune response with minimal adverse effects.

Objective: To evaluate the adjuvant capacity of the association of the rough lipopolysaccharide of Brucella ovis with Gantrez ${ }^{\circledR}$ AN nanoparticles.

Methods: Ovalbumin (allergen model)-containing Gantrez ${ }^{\circledR}$ AN nanoparticles with either encapsulated or coated lipopolysaccharide were prepared and administered intradermally to BALB/c mice in order to evaluate the immune response. Pre-sensitized BALB/c mice were also administered with the formulations and they were challenged with an intraperitoneal injection of ovalbumin. Anaphylactic symptoms, including mortality rates, were evaluated after the challenge.

Results: The intradermal administration of mice with ovalbumin-containing nanoparticles elicited high and sustained specific $\operatorname{IgG}_{1}$ and $\operatorname{IgG}_{2 \mathrm{a}}$ responses. However, the only treatment that totally protected the mice from death after the challenge of induced allergic mice to ovalbumin, required the co-administration of lipopolysaccharide entrapped inside the nanoparticles.

Conclusion: Gantrez ${ }^{\circledR}$ AN nanoparticles with entrapped rough lipopolysaccharide of Brucella ovis protected ovalbumin pre-sensitized BALB/c mice from anaphylactic shock.

Clinical Implications: These results are highly suggestive for the valuable use of Gantrez $^{\circledR}$ nanoparticles combined with lipopolysaccharide of Brucella ovis in immunotherapy with allergens. 
Key words: Gantrez ${ }^{\circledR}$; nanoparticles; adjuvant; lipopolysaccharide; ovalbumin; anaphylactic shock; immunotherapy 


\section{Introduction}

Allergen-specific immunotherapy (SIT) involves repeated administrations of the sensitizing allergen, usually by subcutaneous injection or, more recently, by sublingual application. SIT has been shown to be a robust and clinically effective approach[1, 2], improving the quality of life of the treated individuals, through the reduction of symptoms and medication usage[3].

However, historically, variability in safety and clinical efficacy has limited the widespread application of SIT[4]. Many strategies have been proposed in an attempt to solve these drawbacks, including the use of recombinant allergens and allergen derivatives[5], peptides containing aminoacid sequences of allergen T-cell epitopes[6], low molecular weight fractions of allergen extracts[7], mimotopes[8] and DNA vaccines[9].

The mechanisms by which SIT exerts its effects are not completely known. However, it appears that SIT may modify the response from antigen presenting cells (APCs), and hence of $\mathrm{T}$ and $\mathrm{B}$ cells in order to neutralize the allergen or to induce its tolerogenicity[10].

SIT effects may be enhanced by the use of adjuvants. However, the most common adjuvants used are aluminium hydroxide, calcium phosphate, and tyrosine, which have a good safety record but elicit a poor $\mathrm{T}$ cell response, and the antibodies are mostly of T-helper type 2 (Th2)-type, including $\operatorname{IgE}[11]$. Therefore, the search of new adjuvants is of capital interest. In this context, polymeric nanoparticles could play a key role. This kind of particulate vaccine delivery systems have a lot of advantages such as: i) the protection of the encapsulated active product against its enzymatic inactivation, ii) the increase of the stability of the material incorporated during the manufacturing 
process, transport and storage of such active product and iii) the improvement of the efficacy of the presentation to the APCs[12-14]. In this context, this improvement of the antigen presentation could also be ameliorated by the incorporation of a PAMP (pathogen-associated molecular pattern) to nanoparticles.

The dendritic cells (DCs) are APCs involved in initiating, directing and controlling both innate and adaptive immune responses $[15,16]$. The recognition of the antigens by the DCs is mediated by their toll-like receptors (TLRs) located on their surface. TLRs are able to recognize PAMPs of the invading microorganisms, and some examples of PAMPs are lipopolysaccharide from gram negative bacteria [17], unmethylated bacterial CpG DNA sequences [18] or peptidoglycans from gram positive bacteria among others $[19,20]$. For all these reasons the addition of PAMPs to nanoparticles could be a good strategy to induce or promote activation of TLR-mediated signalling pathways in DCs, maturation of DCs and, consecutively, strong activation of antigen-specific $\mathrm{T}$ lymphocytes. In this context some PAMPs, such as lipopolysaccharide or lipid A (which is known to be the region of the lipopolysaccharide responsible for its adjuvant capacity [21]) have been incorporated into some vehicles such as microparticles $[22,23]$ or nanoparticles $[24,25]$ in order to enhance their adjuvant effect. However, a main drawback when using LPS is its intrinsic toxicity [15].

Therefore, in this investigation it was selected a rough lipopolysaccharide from Brucella ovis, which is known to be low-endotoxic [16]. Brucella possesses an unconventional non-endotoxic lipopolysaccharide that confers resistance to antimicrobial attacks and modulates the host immune response. In this context, Brucella LPS, as a PAMP, promote production of IL-2 and IFN- $\gamma$, but not IL-4, assisting as a 
potential carrier for vaccine development in situations requiring a strong Th1-like response for protection against even xeno-infections [17-21].

Hence, Gantrez ${ }^{\circledR}$ nanoparticles containing OVA, as model allergen, and LPS of Brucella ovis were prepared. The effect of LPS location (coating the surface or encapsulated into the matrix) in the carriers was evaluated in immunization studies as well as in sensitization experiments and further challenge against OVA. 


\section{Methods}

\subsection{Chemicals}

Gantrez $^{\circledR}$ AN 119 [poly(methyl vinyl ether-co-maleic anhydride); MW 200,000] was kindly gifted by ISP (Barcelona, Spain). Ovalbumin (OVA) (grade V), 1.3diaminopropane (DP), 2,2'-Azino-bis(3-ethylbenzo-thiazoline-6-sulfonic acid) diammonium salt (ABTS) and alum were purchased from Sigma-Aldrich Chemie (Germany). The peroxidase immunoconjugates $\left(\mathrm{GAM} / \mathrm{IgG}_{1} / \mathrm{PO}\right.$ and $\left.\mathrm{GAM} / \mathrm{IgG}_{2 \mathrm{a}} / \mathrm{PO}\right)$ were obtained from Nordic Immunology (The Netherlands). The IL-10 ELISA kit was purchased from Biosource International (California, USA). All other chemicals used were of reagent grade and obtained from Merck (Spain).

\subsection{Rough lipopolysaccharide (LPS) of Brucella ovis extraction}

To prepare cells for extraction, tryptic soy broth (TSB) flask were inoculated with fresh cultures of Brucella ovis REO 198 strain, and incubated at $37^{\circ} \mathrm{C}$ for 3 days in air, under constant shaking. The rough lipopolysaccharide fraction was obtained from complete cells as described previously by the phenol-chloroform-petroleum ether extraction method $[22,23]$.

\subsection{Preparation of nanoparticles}


Gantrez $^{\circledR}$ nanoparticles were prepared by a solvent displacement method previously described[24].

\subsubsection{Preparation of OVA-entrapped nanoparticles $\left(O V A^{i n}-N P\right)$}

$\mathrm{OVA}^{\mathrm{in}}$-NP was prepared as described elsewhere[25]. Briefly, $5 \mathrm{mg}$ OVA were dispersed in $1 \mathrm{~mL}$ acetone by ultrasonication (Microson ${ }^{\mathrm{TM}}$ ) for $1 \mathrm{~min}$ under cooling. The OVA dispersion was then added to $4 \mathrm{~mL}$ acetone containing $100 \mathrm{mg}$ Gantrez ${ }^{\circledR}$ and the mixture was stirred for $30 \mathrm{~min}$ at room temperature. Then, the polymer was desolvated by the addition of $20 \mathrm{~mL}$ ethanol: water phase (1:1 by volume). The organic solvents were eliminated under reduced pressure (Büchi R-144, Switzerland) and the resulting nanoparticles dispersed in the aqueous media were cross-linked by incubation with $5 \mu \mathrm{g}$ $\mathrm{DP} / \mathrm{mg}$ copolymer for 5 min under magnetic stirring at room temperature. Nanoparticles were purified by centrifugation and lyophilised using sucrose $5 \%$ as crioprotector.

\subsubsection{Preparation of LPS-coated/OVA-entrapped nanoparticles $\left(O V A^{\text {in }}\right.$-LPS ${ }^{\text {out }}$-NP)}

$5 \mathrm{mg}$ OVA were dispersed in $1 \mathrm{~mL}$ acetone by ultrasonication $\left(\right.$ Microson $^{\mathrm{TM}}$ ) for 1 min under cooling. The OVA dispersion was then added to $4 \mathrm{~mL}$ acetone containing $100 \mathrm{mg}$ Gantrez ${ }^{\circledR}$ and the mixture was stirred for $30 \mathrm{~min}$ at room temperature. Then, the polymer was desolvated by the addition of $20 \mathrm{~mL}$ ethanol: water phase (1:1 by volume). The organic solvents were eliminated under reduced pressure (Büchi R-144, Switzerland). The prepared nanoparticles were then incubated with $1 \mathrm{mg}$ LPS in $1 \mathrm{~mL}$ of water for $1 \mathrm{~h}$ at room temperature under magnetic stirring. Nanoparticles were purified by centrifugation and lyophilised as described above. 


\subsubsection{Preparation of OVA and LPS-entrapped in nanoparticles $\left(O V A^{i n}-L P S^{i n}-N P\right)$}

$5 \mathrm{mg}$ OVA were dispersed in $1 \mathrm{~mL}$ acetone by ultrasonication (Microson ${ }^{\mathrm{TM}}$ ) for 1 min under cooling, similarly, $1 \mathrm{mg}$ LPS was also dispersed in $1 \mathrm{~mL}$ acetone by ultrasonication $\left(\right.$ Microson $\left.^{\mathrm{TM}}\right)$ for 1 min under cooling. The OVA and the LPS dispersions were added to $3 \mathrm{~mL}$ acetone containing $100 \mathrm{mg} \mathrm{Gantrez}{ }^{\circledR}$ and stirred for 30 min at room temperature. Then, the desolvation of the polymer was induced by the addition of $20 \mathrm{~mL}$ ethanol: water phase (1:1 by volume). The organic solvents were eliminated under reduced pressure (Büchi R-144, Switzerland). The resulting nanoparticles dispersed in the aqueous media were cross-linked by incubation with $5 \mu \mathrm{g}$ $\mathrm{DP} / \mathrm{mg}$ copolymer for $5 \mathrm{~min}$ under magnetic stirring at room temperature. The formulation was purified by centrifugation and lyophilised as described above.

\subsection{Characterisation of nanoparticles}

The particle size and the zeta potential of nanoparticles were determined by photon correlation spectroscopy and electrophoretic laser doppler anemometry, respectively, using a Zetamaster analyser system (Malvern Instruments, UK). The samples were diluted with deionized water and measured at room temperature with a scattering angle of $90^{\circ}$. All measurements were performed in triplicate.

The morphological characteristics of the nanoparticles were observed by scanning electron microscopy (LEO Electron Microscopy Inc, Thornwood, NY) operating at $3 \mathrm{kV}$ with a filament current of about $0.5 \mathrm{~mA}$. Prior to observation, the 
nanoparticles were coated with a platinum laker of about $2 \mathrm{~nm}$ using a Cressington sputter-coated $208 \mathrm{HR}$ with a rotatory-planetary-tilt stage, equipped with a MTM-20 thickness controller.

The quantification of the amount of OVA associated to nanoparticles was determined using HPLC. The analysis was performed in a HPLC model 1050 series LC, Agilent (Waldbornn, Germany) coupled with fluorescence detector. Data were analyzed by Hewlett-Packard computer using the Chem-Station G2171 program. The separation was carried out at $25^{\circ} \mathrm{C}$ on a reversed-phase Zorbax GF-25 column (4.6 mm x $250 \mathrm{~mm}$; particles size $4 \mu \mathrm{m}$ ) obtained from Agilent Technologies (California, USA). The mobile phase composition was phosphate buffer $(130 \mathrm{mM} \mathrm{NaOH}, 20 \mathrm{mM} \mathrm{KCl}, 50 \mathrm{mM}$ $\left.\mathrm{Na}_{2} \mathrm{HPO}_{4}\right) \mathrm{pH} 7$, methanol and water $(40 / 10 / 50 \mathrm{v} / \mathrm{v} / \mathrm{v})$. The flow rate was set to 1 $\mathrm{ml} / \mathrm{min}$ and effluent was monitored with fluorescence detection $\left(\lambda_{\mathrm{exc}}=280 \mathrm{~nm} \quad \lambda_{\mathrm{em}}=340\right.$ $\mathrm{nm})$.

For HPLC analysis, nanoparticles were previously digested with $\mathrm{NaOH} 0.1 \mathrm{~N}$ for $24 \mathrm{~h}$ at $4^{\circ} \mathrm{C}$. Then, the samples were transferred to auto-sampler vials, capped and placed in the HPLC auto-sampler.

The amount of associated LPS to nanoparticles was indirectly estimated by determining one of its exclusive markers, 2-keto-3-deoxy-octulosonic acid (KDO), by the thiobarbiturate acid method[26]. For this purpose, a solution containing digested nanoparticles $\left(\mathrm{NaOH} 0.1 \mathrm{~N}, 24 \mathrm{~h}, 4^{\circ} \mathrm{C}\right)$ was added to 5 volumes of a solution of methanol and $1 \%$ methanol saturated with sodium acetate to precipitate the LPS content. The pellet obtained was then resuspended in $0.2 \%$ SDS solution and used in the KDO assay. Each sample was assayed in triplicate and results were expressed as the amount of LPS (in $\mu \mathrm{g}$ ) per mg nanoparticles. 


\subsection{Immunization studies}

Animal protocols were performed in compliance with the regulations of the Ethical Committee of the University of Navarra in line with the European legislation on animal experiments (86/609/EU).

BALB/c mice, females of 8 weeks old (supplied by Harlan Interfauna Ibérica, Spain), were randomized into 6 groups of 5 mice. Animals were intradermally immunised once on day 0 , with $10 \mu \mathrm{g}$ OVA incorporated in one of the following formulations: i) OVA-entrapped nanoparticles $\left(\mathrm{OVA}^{\mathrm{in}}-\mathrm{NP}\right)$; ii) OVA-entrapped and LPS-coated nanoparticles (OVA $\left.{ }^{\text {in }}-L S^{\text {out }}-N P\right)$; iii) OVA and LPS-entrapped nanoparticles $\left(\mathrm{OVA}^{\text {in }}{ }^{-\mathrm{LPS}^{\text {in }}}\right.$-NP); iv) OVA adsorbed in alhydrogel (OVA-Alum) and v) free OVA dissolved in sterile PBS.

Blood samples from the the retroorbital plexus were collected on days $0,7^{\text {th }}$, $14^{\text {th }}, 28^{\text {th }}, 35^{\text {th }}, 42^{\text {nd }}$ and $49^{\text {th }}$ post-immunization. The samples were centrifuged $(3000 \mathrm{x}$ g, $10 \mathrm{~min}$ ) and the resulting sera were pooled. Finally, each pool was diluted 1:10 in PBS and stored at $-80^{\circ} \mathrm{C}$ until analysis.

\subsection{Quantification of anti-OVA antibodies in serum}

Specific antibodies against OVA ( $\operatorname{IgG}_{1}$ and $\operatorname{IgG}_{2 \mathrm{a}}$ ) were determined in the pooled sera by indirect ELISA. Briefly, microtiter wells (cliniplatte EB, Labsystems, Finland) were coated with OVA $(1 \mu \mathrm{g} /$ well $)$ at $4{ }^{\circ} \mathrm{C}$ overnight. Serum samples were added in two-fold serial dilutions in PBS-Tween 20 (1\%) starting with 1:40, and 
incubated at $37{ }^{\circ} \mathrm{C}$ for $4 \mathrm{~h}$. Anti-mouse $\operatorname{IgG}_{1}$ or $\operatorname{IgG}_{2 a}$ peroxidase conjugates diluted 1:1000 in PBS-Tween $20(1 \%)$ were added followed by the substrate chromogen solution $\left(\mathrm{H}_{2} \mathrm{O}_{2}\right.$-ABTS). Optical density (OD) was determined at $\lambda_{\max } 405 \mathrm{~nm}$ (iEMS Reader MF de Labsystems, Finlandia). Measurements were performed by triplicate and data were expressed as the reciprocal of a serum dilution whose optical density was 0.2 above blank samples.

\subsection{Quantification of $I L-10$}

The IL-10 in the pooled sera of immunized mice was quantified by a commercial ELISA kit of Biosource International (California, USA). Measurements were performed by triplicate and data were expressed as $\mathrm{pg} / \mathrm{mL}$ of IL-10 in sera.

\subsection{Sensitization, vaccination and challenge studies}

The scheme of the experiment is shown in Figure 1. Briefly, BALB/c mice, females of 8 weeks old (supplied by Harlan Interfauna Ibérica, Spain), were sensitized by intraperitoneal injection of $50 \mu \mathrm{g}$ of OVA emulsified in $1 \mathrm{mg}$ alum (alhydrogel) adjuvant (Sigma-Aldrich Chemie, Germany) in a total volume of $150 \mu \mathrm{L}$ on days $1^{\text {st }}$ and $8^{\text {th }}$. On days $14^{\text {th }}, 17^{\text {th }}$ and $20^{\text {th }}$, the animals (5 mice per group) received intradermal injections with $3 \mu \mathrm{g}$ of OVA each incorporated in either OVA ${ }^{\text {in }}-\mathrm{NP}, \mathrm{OVA}^{\text {in }}$-LPS ${ }^{\text {out }}$-NP or OVA ${ }^{\text {in }}$ LPS $^{\text {in }}$-NP. As controls, OVA dispersed in Alum (Ova-Alum) and PBS were used. Finally on day $35^{\text {th }}$ the animals were challenged by an injection of $1 \mathrm{mg}$ of OVA by intraperitoneal route. 
Blood samples from the the retroorbital plexus were collected on days $0,13^{\text {th }}$, $27^{\text {th }}$ and $33^{\text {th }}$. The samples were centrifuged (3000 x g, $\left.10 \mathrm{~min}\right)$ and the resulting sera were pooled. Finally, each pool was diluted $1: 10$ in $\mathrm{PBS}$ and stored at $-80^{\circ} \mathrm{C}$ until analysis.

\subsubsection{Determination of total immunoglobulin E antibody levels in serum}

To determine the IgE antibody level, microtitre plates (Nunc-ImmunoTM Plate, Roskilde, Denmark) were coated overnight at $4^{\circ} \mathrm{C}$ with anti-mouse $\mathrm{IgE}$ antibodies (pH 9.5) (BD OptEIATM Set Mouse IgE, BD Biosciences, Franklin Lakes, NJ, USA). Thereafter, plates were washed with PBS-Tween 20 0.05\% (PBS-T20) and blocked for $1 \mathrm{~h}$ at room temperature with PBS-FBS 10\%, washed again and sera dilutions were incubated for $2 \mathrm{~h}$ at room temperature. After washing, plates were incubated for $1 \mathrm{~h}$ at room temperature with a mixture of anti-IgE antibodies marked with biotin and horseradish peroxidase-conjugated. Later, plates were washed under the same conditions and 2,20-azino-bis(3-ethylbenzothiazoline-6-sulphonic acid) in citric acid (pH 4.0) and hydrogen peroxide was added. The optical density was measured at 405 $\mathrm{nm}$ in a microplate autoreader (iEMS Reader MF, Labsystems).

\subsubsection{Histamine quantification}

Histamine release test was performed on heparinized whole blood from the retro-orbital plexus obtained before and $30 \mathrm{~min}$ after the challenge. Samples were lysed using perchloric acid $(1.4 \% \mathrm{w} / \mathrm{w})$ to determine whole blood histamine content. The resulting suspensions were centrifuged (10 $\mathrm{min}, 800 \mathrm{x} \mathrm{g}$ ) and histamine production was 
assayed by a fluorometric method as previously described[27] using a Technicon II Analyzer (Technicon Instrument Corp., USA).

\subsubsection{Evaluation of anaphylaxis}

The body temperature changes associated with anaphylactic shock were monitored by measuring the rectal temperature[28] without general anesthesia before and $10 \mathrm{~min}$ after the challenge. Anaphylactic symptoms (activity, bristly hair, and cyanosis) were evaluated 30 min after the challenge using a scoring system modified from previous reports[29, 30]. Reactions severity was classified in following categories depending on their gravity: i) (-) absent; ii) (+) weak; iii) (++) moderate; and iv) (+++) strong, and the mobility was classified in i) low or ii) normal, depending on the activity of the animals. Finally, the mortality rates were recorded $24 \mathrm{~h}$ after intraperitoneal challenge.

\subsection{Statistical analysis}

The physico-chemical characteristics were compared using the Student t-Test. $P$ values $<0.05$ were considered significant. For the evaluation of the histamine increase and temperature decrease, statistical comparisons were performed using the one-way analysis of variance test (ANOVA) and Tukey HSD test. $P<0.05$ was considered as a

statistically significant difference. All calculations were performed using SPSS $^{\circledR}$ statistical software program $\left(\operatorname{SPSS}^{\circledR} 10\right.$, Microsoft, USA). 


\section{Results}

\subsection{Characterisation of Gantrez ${ }^{\circledR}$ nanoparticles}

The main physico-chemical characteristics of Gantrez ${ }^{\circledR}$ formulations are summarised in Table 1. The size of OVA nanoparticles were significantly higher than empty nanoparticles (NP) $(\mathrm{p}<0.05)$; however, the presence of LPS in the OVA formulations did not affect the size of the nanoparticles. Overall, nanoparticle batches were found to be homogeneous spheres (Figure 2). In addition, no important difference was visualized when compared SEM photographs of nanoparticles containing only OVA $\left(\mathrm{OVA}^{\mathrm{in}}\right.$-NP, Figure 2a) with nanoparticles containing also LPS $\left(\mathrm{OVA}^{\mathrm{in}}-\mathrm{LPS}^{\mathrm{in}}-\mathrm{NP}\right.$, Figure $2 \mathrm{~b}$ ). The OVA content was about $25-30 \mu \mathrm{g} / \mathrm{mg}$ in all cases and the LPS amount was around $14 \mu \mathrm{g} / \mathrm{mg}$ nanoparticles.

Concerning the OVA content, it is interesting to note that the addition of LPS slightly decreased the OVA content and the encapsulation efficiency.

3.2. Antibody response in BALB/c mice after intradermal administration of the OVAnanoparticle formulations

Figure 3 shows the anti-OVA $\operatorname{IgG}_{1}$ and $\mathrm{IgG}_{2 \mathrm{a}}$ titres (Th2 and Th1 markers, respectively) in sera after intradermal immunization of mice with the different formulations. All nanoparticle formulations induced a similar profile characterised by a short lag-time, of about 1 week, followed by a rapid increase of anti-OVA $\operatorname{IgG}_{1}$ levels for at least 3 weeks. At the end of this period (day $28^{\text {th }}$ ), a plateau of antibody levels was reached and maintained till the end of the experiment (day $49^{\text {th }}$ ). The levels of anti-OVA 
$\mathrm{IgG}_{1}$ antibodies were always higher for nanoparticle formulations than those induced by the control OVA-Alum. On the other hand, the presence of LPS on the surface of the nanoparticles $\left(\mathrm{OVA}^{\mathrm{in}}\right.$-LPS ${ }^{\text {out }}$-NP) increased the level of $\mathrm{IgG}_{2 \mathrm{a}}$ antibodies against OVA (Th1 response). Free OVA titres were close to the basal line.

\subsection{IL-10 quantification}

Figure 4 shows the IL-10 concentration in sera after intradermal immunization of mice with the different nanoparticles formulations. OVA ${ }^{\text {in }}$-NP appeared to be the most effective formulation in inducing IL-10 production. On the other hand, the association of LPS to the nanoparticles decreased the seric levels of IL- 10 . Significantly, a peak of IL-10 concentration was found on day $14^{\text {th }}$ for all OVAentrapped nanoparticles,

\subsection{Immunotherapeutic schedule}

The induced OVA-allergic mice received the immunotherapeutic schedule previously described, and IgE levels were monitorised on days $0,13,27$ and 33 . These levels were found to be higher for the animals immunized with OVA-Alum than those with $\mathrm{OVA}^{\mathrm{in}}$-LPS $^{\text {out }}$-NP and $\mathrm{OVA}^{\mathrm{in}}$-LPS ${ }^{\text {in }}$-NP (Figure 5) during all the experiment. Furthermore, at day 35, the amount of IgE for the OVA-Alum group was two times higher than the one produced by mice immunized with every OVA nanoparticles formulations $\left(\mathrm{OVA}^{\text {in }}-\mathrm{NP}, \mathrm{OVA}^{\text {in }}-\mathrm{LPS}^{\text {out }}-\mathrm{NP}\right.$ and $\left.\mathrm{OVA}^{\text {in }}-\mathrm{LPS}^{\mathrm{in}}-\mathrm{NP}\right)$. 
On day $35^{\text {th }}$ the animals were challenged with OVA. In order to analyse the intensity of the anaphylactic shock, several parameters were determined. Figure 6 shows the difference of histamine blood levels before the challenge and 30 minutes later. Groups treated with either OVA ${ }^{\text {in }}-\mathrm{LPS}^{\mathrm{in}}$-NP or OVA ${ }^{\text {in }}$-NP showed a significant lower increase of the histamine levels in comparison with the control groups (OVAAlum and PBS). In contrast, the group of animals treated with OVA ${ }^{\text {in }}$-LPS ${ }^{\text {out }}$-NP did not show a significant difference with the controls.

Table 2 shows the overall anaphylactic symptoms score including the mortality rate. $\mathrm{OVA}^{\text {in }}-\mathrm{NP}, \mathrm{OVA}^{\text {in }}-\mathrm{LPS}^{\text {out }}-\mathrm{NP}$ and $\mathrm{OVA}^{\text {in }}-\mathrm{LPS}^{\text {in }}$-NP groups showed a slightly lower decrease on the body temperature than the controls (OVA-Alum and PBS), although, the differences were not significant $(\mathrm{p}<0.05)$. The piloerection and cyanosis seemed to be lower for $O V A^{\text {in }}-\mathrm{NP}$ and $O V A^{\text {in }}-$ LPS $^{\text {in }}$-NP than for the other formulations. Furthermore, the mobility seemed not to be affected in the animals treated with $\mathrm{OVA}^{\text {in }}$-LPS ${ }^{\text {in }}$-NP, while for the other groups the animals were found to be static with a high difficulty to coordinate any simple movement. Finally, the OVA ${ }^{\text {in }}$ LPS $^{\text {in }}$-NP group protected the animals from death, while, for the other groups tested, the mortality rate was between 40 and $80 \%$. 


\section{Discussion}

The physicochemical and biodegradation properties of some nanoparticle formulations may be worthy as useful imunoadjuvants[31-33]. In the context of the immunotherapy of allergic processes, potent adjuvants are required. Thus, and based on previous studies with nanoparticles of the polymer Gantrez ${ }^{\circledR}$ AN[25], the aim of the present work was to study the effect of the incorporation of an immunostimulant, such as the low-endotoxic LPS from Brucella ovis[34], on the adjuvant capacity of these nanoparticles. The special chemical nature of Gantrez ${ }^{\circledR}$ nanoparticles may afford the binding on their exposed chemical reactive groups of microbial markers, that may interact with scavenger ligands on the immune cells involved in signal transduction and the secretion of cytokines[34]. For this purpose, Gantrez ${ }^{\circledR}$ nanoparticles containing ovalbumin (OVA) were prepared. This protein was incorporated during the manufacture process (OVA-entrapped nanoparticles) as described previously[25], and the LPS was incorporated either during the nanoparticle manufacture (LPS ${ }^{\text {in }}$, entrapped) or after the preparation of nanoparticles (LPS ${ }^{\text {out }}$, coating).

When these formulations were intradermally administered to mice, the presence of the LPS on the NP $\left(\mathrm{OVA}^{\text {in }}{ }^{-\mathrm{LPS}^{\text {out }}}{ }^{\mathrm{NP}}\right)$ increased the OVA-specific $\mathrm{IgG}_{2 \mathrm{a}}$ levels (Th1 marker). On the contrary, the levels of $\operatorname{IgG}_{1}$ (Th2 marker) were not affected by the presence of the LPS. These results are in agreement with our previous observations related with the ability of Brucella ovis LPS to promote the production of Th1 cytokines[35]. Thus, OVA ${ }^{\text {in }}$-LPS ${ }^{\text {out }}$-NP (LPS coating the surface of nanoparticles) is "mimicking" the gram negative bacteria structure with the LPS on the surface, activating the Th1 pathway. Other authors have used smooth Brucella spp. lipopolysaccharides in assisting as a potential carrier for vaccine development in 
situations requiring a strong Th1-like response for protection against even xenoinfections[17, 19-21, 36], but this is the first report describing the capability of Brucella ovis rough LPS as an immunostimulant.

From the immunological point of view, an allergic episode is characterized by the presence of $\operatorname{IgE}$ and $\mathrm{IgG}_{1}$, produced by B lymphocytes after the polarization of $\mathrm{Th}$ naïve lymphocyte into a Th2 subset population[37]. As it is well known, immunotherapy in humans should be based on the decrease of the Th2 by enhancing the Th1, and this balance is achieved by increasing the activity of the $\mathrm{T}_{\text {reg }}$ lymphocytes[38]. $\mathrm{T}_{\text {reg }}$ cytokines (IL-10, TNF- $\alpha$ ) play a key role in preventing IgE and Th2 expansion[39, 40]. Thus, we have demonstrated that LPS-nanoparticles do exert an effect on the $T_{\text {reg }}$ lymphocites, since IL-10 could be detected after immunization. Moreover, only when OVA was associated to Gantrez ${ }^{\circledR}$ nanoparticles, IL-10 could be detected in sera (see Figure 4).

In order to evaluate the therapeutic effect of these formulations with or without LPS on a model of OVA-sensitized mice, the mice were treated with the OVAentrapped nanoparticles with or without LPS by intradermal route and finally were challenged and the different anaphylactic symptoms were observed. The monistorisation of the total IgE during the experiment indicated that all the formulations of OVAGantrez nanoparticles were able to decrease this antibody isotype, which is related to the allergic episodes. Moreover, the formulations with LPS of Brucella ovis, showed levels of total IgE even lower than the OVA-NP formulation.

On the other hand, histamine levels, one the most dangerous substance released during anaphylaxis, was much lower $(\mathrm{p}<0.005)$ for LPS-entrapped nanoparticles $\left(\mathrm{OVA}^{\mathrm{in}}-\mathrm{LPS}^{\mathrm{in}}\right.$-NP) than for control groups (Figure 6). These results correlated well with 
the temperature decrease after the challenge (Table 2). However, the ultimate parameter to test the efficacy of the immunization was the protection against mortality. Again, $\mathrm{OVA}^{\mathrm{in}}{ }^{-\mathrm{LPS}^{\mathrm{in}}}{ }_{-\mathrm{NP}}$ was found to be the best formulation. In fact, OVA ${ }^{\mathrm{in}}$-LPS $^{\mathrm{in}}$-NP protected all the mice from death, in contrast to the control groups immunized with OVA-Alum or PBS. However, when the LPS was coating the nanoparticles $\left(\mathrm{OVA}^{\mathrm{in}}\right.$ LPS $^{\text {out }}$-NP), the mice were not protected, and the mortality rate was similar than that observed for the untreated group. The appropriate co-stimulation of the dendritic TLR-4 with the LPS at the time of allergen (OVA) exposure would develop a protective Th1 immune response. When the LPS is encapsulated in the nanoparticles with the OVA $\left(\mathrm{OVA}^{\mathrm{in}}-\mathrm{LPS}^{\mathrm{in}}-\mathrm{NP}\right)$, both LPS and OVA are supposed to release at the same time, being more effective the OVA presentation. However, when the OVA is entrapped in the nanoparticles and the LPS is coating the surface (OVA $\left.{ }^{\text {in }}-\mathrm{LPS}^{\text {out }}-\mathrm{NP}\right)$, the LPS would be released first followed by the OVA.

We have demonstrated the ability of Gantrez ${ }^{\circledR}$ nanoparticles to induce high levels of IL-10 thus showing highly interesting adjuvant properties for immunotherapy. However, the most remarkable finding is the capability of combined use of the innocuous rough LPS from Brucella ovis and Gantrez ${ }^{\circledR}$ nanoparticles to protect from anaphylactic shock. And, it is even more interesting when considering that protection from anaphylactic death is not usually described in the literature [41-44]. Therefore, this effect is a significant finding for its application in immunotherapy. 


\section{Acknowledgements}

This research was supported by "Gobierno de La Rioja", "Fundación Universitaria de Navarra", ISP Corp., and grants from the "Ministerio de Ciencia y Tecnología" (SAF2001-0690-C03; AGL2004-07088-C03-02/GAN) in Spain. Authors want also to thank Audrey Valette (UPR CNRS 2801, Thiais, France), Madeleine Besnard (UMR CNRS 8612, Chatenay Malabry, France) for their help in the characterisation of nanoparticles by microscopy and Rocío Martinez and Maite Hidalgo (Pharmacy and Pharmaceutical Technology Department, University of Navarra, Pamplona, Spain). 


\section{References}

1. Durham SR, Walker SM, Varga EM, Jacobson MR, O'Brien F, Noble W, Till SJ, Hamid QA, Nouri-Aria KT, Long-term clinical efficacy of grass-pollen immunotherapy. N Engl J Med 1999;341: 468-475.

2. Moller C, Dreborg S, Ferdousi HA, Halken S, Host A, Jacobsen L, Koivikko A, Koller DY, Niggemann B, Norberg LA, Urbanek R, Valovirta E, Wahn U, Pollen immunotherapy reduces the development of asthma in children with seasonal rhinoconjunctivitis (the PAT-study). J Allergy Clin Immunol 2002;109: 251-256.

3. Walker SM, Pajno GB, Lima MT, Wilson DR, Durham SR, Grass pollen immunotherapy for seasonal rhinitis and asthma: a randomized, controlled trial. J Allergy Clin Immunol 2001;107: 87-93.

4. Bernstein DI, Wanner M, Borish L, Liss GM, Twelve-year survey of fatal reactions to allergen injections and skin testing: 1990-2001. J Allergy Clin Immunol 2004;113: 1129-1136.

5. Linhart B, Valenta R, Molecular design of allergy vaccines. Curr Opin Immunol 2005; 17: 646655.

6. Fellrath JM, Kettner A, Dufour N, Frigerio C, Schneeberger D, Leimgruber A, Corradin G, Spertini F, Allergen-specific T-cell tolerance induction with allergen-derived long synthetic peptides: results of a phase I trial. J Allergy Clin Immunol 2003;111: 854-861.

7. Malley A, Perlman F, Induction of both reaginic and blocking antibodies with a low molecular weight fraction of timothy pollen extract. J Allergy 1969;43: 59-64.

8. Ganglberger E, Barbara S, Scholl I, Wiedermann U, Baumann S, Hafner C, Breiteneder H, Suter M, Boltz-Nitulescu G, Scheiner O, Jensen-Jarolim E, Monovalent fusion proteins of IgE mimotopes are safe for therapy of type I allergy. Faseb J 2001;15: 2524-2526.

9. Hsu CH, Chua KY, Tao MH, Lai YL, Wu HD, Huang SK, Hsieh KH, Immunoprophylaxis of allergen-induced immunoglobulin E synthesis and airway hyperresponsiveness in vivo by genetic immunization. Nat Med 1996;2: 540-544.

10. Jayasekera NP, Toma TP, Williams A, Rajakulasingam K, Mechanisms of immunotherapy in allergic rhinitis. Biomed Pharmacother 2006.

11. Francis JN, Durham SR, Adjuvants for allergen immunotherapy: experimental results and clinical perspectives. Curr Opin Allergy Clin Immunol 2004;4: 543-548.

12. Couvreur P, Puisieux F, Nano- and microparticles for the delivery of polypeptides and proteins. Advanced Drug Delivery Reviews 1993;10: 141-162.

13. O'Hagan DT, Rappuoli R, Novel approaches to vaccine delivery. Pharm Res 2004;21: 15191530 .

14. Singh M, O'Hagan DT, Recent advances in vaccine adjuvants. Pharm Res 2002;19: 715-728.

15. Rietschel ET, Brade L, Brandenburg K, Flad HD, de Jong-Leuveninck J, Kawahara K, Lindner B, Loppnow H, Luderitz T, Schade U, et al., Chemical structure and biologic activity of bacterial and synthetic lipid A. Rev Infect Dis 1987;9 Suppl 5: S527-536.

16. Moreno E, Jones LM, Berman DT, Immunochemical characterization of rough Brucella lipopolysaccharides. Infect Immun 1984;43: 779-782. 
17. Agranovich I, Scott DE, Terle D, Lee K, Golding B, Down-regulation of Th2 responses by Brucella abortus, a strong Th1 stimulus, correlates with alterations in the B7.2-CD28 pathway. Infect Immun 1999;67: 4418-4426.

18. Cardoso PG, Macedo GC, Azevedo V, Oliveira SC, Brucella spp noncanonical LPS: structure, biosynthesis, and interaction with host immune system. Microb Cell Fact 2006;5: 13.

19. Lapham C, Golding B, Inman J, Blackburn R, Manischewitz J, Highet P, Golding H, Brucella abortus conjugated with a peptide derived from the V3 loop of human immunodeficiency virus (HIV) type 1 induces HIV-specific cytotoxic T-cell responses in normal and in CD4+ celldepleted BALB/c mice. J Virol 1996;70: 3084-3092.

20. Vemulapalli R, He Y, Boyle SM, Sriranganathan N, Schurig GG, Brucella abortus strain RB51 as a vector for heterologous protein expression and induction of specific Th1 type immune responses. Infect Immun 2000;68: 3290-3296.

21. Zaitseva MB, Golding H, Betts M, Yamauchi A, Bloom ET, Butler LE, Stevan L, Golding B, Human peripheral blood CD4+ and CD8+ T cells express Th1-like cytokine mRNA and proteins following in vitro stimulation with heat-inactivated Brucella abortus. Infect Immun 1995;63: 2720-2728.

22. Gamazo C, Winter AJ, Moriyon I, Riezu-Boj JI, Blasco JM, Diaz R, Comparative analyses of proteins extracted by hot saline or released spontaneously into outer membrane blebs from field strains of Brucella ovis and Brucella melitensis. Infect Immun 1989;57: 1419-1426.

23. Galanos C, Luderitz O, Westphal O, A new method for the extraction of R lipopolysaccharides. Eur J Biochem 1969;9: 245-249.

24. Arbos P, Arangoa MA, Campanero MA, Irache JM, Quantification of the bioadhesive properties of protein-coated PVM/MA nanoparticles. Int J Pharm 2002;242: 129-136.

25. Gómez S, Gamazo S, San Roman B, Vauthier C, Ferrer M, Irache JM, Development of a novel vaccine delivery system based on Gantrez nanoparticles. Journal of Nanoscience and Nanotechnology 2006;6: 3283-3289.

26. Warren L, The thiobarbituric acid assay of sialic acids. J Biol Chem 1959;234: 1971-1975.

27. Castillo JG, Gamboa PM, Oehling A, Wong E, de la Cuesta CG, Variations in antigen-specific histamine release related with immunotherapeutic treatment. Allergol Immunopathol (Madr) 1989;17: 149-153.

28. Watanabe N, Matsuda E, Masuda A, Nariai K, Shibasaki T, The effects of fexofenadine on eosinophilia and systemic anaphylaxis in mice infected with Trichinella spiralis. Int Immunopharmacol 2004;4: 367-375.

29. Stampfli MR, Cwiartka M, Gajewska BU, Alvarez D, Ritz SA, Inman MD, Xing Z, Jordana M, Interleukin-10 gene transfer to the airway regulates allergic mucosal sensitization in mice. Am J Respir Cell Mol Biol 1999;21: 586-596.

30. Poulsen OM, Hau J, Kollerup J, Effect of homogenization and pasteurization on the allergenicity of bovine milk analysed by a murine anaphylactic shock model. Clin Allergy 1987;17: 449-458.

31. Rydell N, Stertman L, Sjoholm I, Starch microparticles as vaccine adjuvant. Expert Opin Drug Deliv 2005;2: 807-828. 
32. Batanero E, Barral P, Villalba M, Rodriguez R, Encapsulation of Ole e 1 in biodegradable microparticles induces Th1 response in mice: a potential vaccine for allergy. J Control Release 2003;92: 395-398.

33. Singh M, Carlson JR, Briones M, Ugozzoli M, Kazzaz J, Barackman J, Ott G, O'Hagan D, A comparison of biodegradable microparticles and MF59 as systemic adjuvants for recombinant gD from HSV-2. Vaccine 1998;16: 1822-1827.

34. Weiss DS, Takeda K, Akira S, Zychlinsky A, Moreno E, MyD88, but not toll-like receptors 4 and 2, is required for efficient clearance of Brucella abortus. Infect Immun 2005;73: 5137-5143.

35. Murillo M, Goni MM, Irache JM, Arangoa MA, Blasco JM, Gamazo C, Modulation of the cellular immune response after oral or subcutaneous immunization with microparticles containing Brucella ovis antigens. J Control Release 2002;85: 237-246.

36. Huang L, Krieg AM, Eller N, Scott DE, Induction and regulation of Th1-inducing cytokines by bacterial DNA, lipopolysaccharide, and heat-inactivated bacteria. Infect Immun 1999;67: 62576263.

37. Romagnani S, Immunologic influences on allergy and the TH1/TH2 balance. J Allergy Clin Immunol 2004;113: 395-400.

38. Akdis CA, Blaser K, Akdis M, Mechanisms of allergen-specific immunotherapy. Chem Immunol Allergy 2006;91: 195-203.

39. Robinson DS, Regulation: the art of control? Regulatory T cells and asthma and allergy. Thorax 2004;59: 640-643.

40. Cottrez F, Hurst SD, Coffman RL, Groux H, T regulatory cells 1 inhibit a Th2-specific response in vivo. J Immunol 2000;165: 4848-4853.

41. Moisan J, Camateros P, Thuraisingam T, Marion D, Koohsari H, Martin P, Boghdady ML, Ding A, Gaestel M, Guiot MC, Martin JG, Radzioch D, TLR7 ligand prevents allergen-induced airway hyperresponsiveness and eosinophilia in allergic asthma by a MYD88-dependent and MK2-independent pathway. Am J Physiol Lung Cell Mol Physiol 2006;290: L987-995.

42. Palomares O, Batanero E, Canamero M, Villalba M, Rodriguez R, Prophylactic intranasal treatment with fragments of 1,3-beta-glucanase olive pollen allergen prevents airway inflammation in a murine model of type I allergy. Int Arch Allergy Immunol 2006;139: 175-180.

43. Repa A, Wild C, Hufnagl K, Winkler B, Bohle B, Pollak A, Wiedermann U, Influence of the route of sensitization on local and systemic immune responses in a murine model of type I allergy. Clin Exp Immunol 2004;137: 12-18.

44. Wild JS, Sigounas A, Sur N, Siddiqui MS, Alam R, Kurimoto M, Sur S, IFN-gamma-inducing factor (IL-18) increases allergic sensitization, serum IgE, Th2 cytokines, and airway eosinophilia in a mouse model of allergic asthma. J Immunol 2000;164: 2701-2710. 


\section{Figure legends}

Figure 1. Experimental design. BALB/c mice were sensitized by receiving two intraperitoneal injections of $50 \mu \mathrm{g}$ OVA/Alum. Once the animals were sensitized to OVA, they received the treatments (A) OVA-Alum, PBS, OVA ${ }^{\text {in }}-\mathrm{NP}, \mathrm{OVA}^{\mathrm{in}}-\mathrm{LPS}^{\text {out }}$-NP and $\mathrm{OVA}^{\text {in }}$-LPS ${ }^{\text {in }}$-NP. Finally, on day $35^{\text {th }}$ they were challenged by administering an intraperitoneal injection of $1 \mathrm{mg}$ OVA in solution.

Figure 2. SEM photographs of: a) $\mathbf{O V A}^{\text {in }}$-NP (OVA-entrapped nanoparticles) and b) OVA $^{\text {in }}$-LPS $^{\text {in }}$-NP (OVA and LPS-entrapped nanoparticles).

Figure 3. Anti-OVA $\operatorname{IgG}_{1}$ and $\operatorname{IgG}_{2 \mathrm{a}}$ titres in sera after intradermal immunization with: OVA solution (OVA) (匹), OVA adsorbed in alhydrogel (OVA-Alum) ( $\left.{ }^{\star}\right)$, OVAentrapped nanoparticles $\left(\mathrm{OVA}^{\mathrm{in}}-\mathrm{NP}\right)(\boldsymbol{\Delta}), \quad$ OVA-entrapped and LPS-coated nanoparticles $\left(\mathrm{OVA}^{\text {in }}\right.$ LPS $^{\text {out }}$-NP) $(\Delta)$, and OVA and LPS entrapped nanoparticles $\left(\mathrm{OVA}^{\mathrm{in}}{ }^{\left.-\mathrm{LPS}^{\mathrm{in}}-\mathrm{NP}\right)}\left(\nabla^{\nabla}\right)\right.$ ). The antibody titre is defined as the reciprocal dilution giving an optical density (OD) reading at $405 \mathrm{~nm}$ of $\geq 0.2$.

Figure 4. IL-10 concentration $(\mathrm{pg} / \mathrm{mL})$ in sera after intradermal immunization with OVA solution (OVA) (匹), OVA adsorbed in alhydrogel (OVA-Alum) ${ }^{\star}$ ), blank nanoparticles (NP) (४), OVA-entrapped nanoparticles $\left(\mathrm{OVA}^{\mathrm{in}}-\mathrm{NP}\right)(\boldsymbol{\Delta})$, OVAentrapped and LPS-coated nanoparticles $\left(\mathrm{OVA}^{\text {in }}{ }^{-\mathrm{LPS}^{\text {out }}}{ }_{-} \mathrm{NP}\right)(\Delta)$ and OVA and LPS entrapped nanoparticles $\left(\mathrm{OVA}^{\text {in }}-\mathrm{LPS}^{\mathrm{in}}-\mathrm{NP}\right)\left({ }^{\nabla}\right)$ ). 
Figure 5. Evolution of total $\mathrm{IgE}$ in sera from $\mathrm{BALB} / \mathrm{c}$ mice during the sensitization and challenge study. Mice were sensitized to OVA ( $50 \mu \mathrm{g}$ OVA by an intraperitoneal route, days 1 and 8) and immunized (10 $\mu \mathrm{g}$ OVA, divided in to three doses of $3.33 \mu \mathrm{g}$; (see arrows $(\downarrow)$ in the figures) with OVA adsorbed in aluminium hydroxide (OVAAlum) $\left(^{\star}\right)$ OVA-entrapped nanoparticles $\left(\mathrm{OVA}^{\mathrm{in}}-\mathrm{NP}\right)(\boldsymbol{\Delta})$, OVA-entrapped and LPScoated nanoparticles $\left(\mathrm{OVA}^{\mathrm{in}}-\mathrm{LPS}^{\text {out }}-\mathrm{NP}\right)(\Delta)$ and OVA and LPS entrapped nanoparticles $\left.\left(\mathrm{OVA}^{\mathrm{in}}-\mathrm{LPS}^{\mathrm{in}}-\mathrm{NP}\right)\left({ }^{\nabla}\right)\right)$.

Figure 6. Increase of the histamine blood level after the challenge with $1 \mathrm{mg}$ of OVA i.p. After sensitization to OVA, the different groups of animals were treated (days $14^{\text {th }}$, $17^{\text {th }}$ and $20^{\text {th }}$ ) with OVA-entrapped nanoparticles (OVA $\left.{ }^{\text {in }}-\mathrm{NP}\right)$, OVA-entrapped and

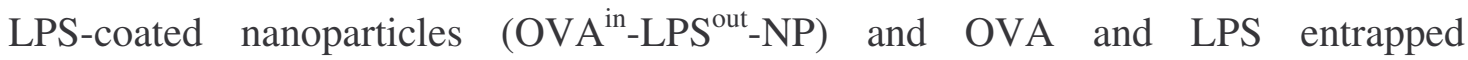
nanoparticles $\left(\mathrm{OVA}^{\text {in }}\right.$-LPS ${ }^{\text {in }}$-NP). OVA adsorbed in alhydrogel (OVA-Alum) and PBS were used as controls. $(*)$ represents statistical difference $(\mathrm{p}<0.5)$. 
Table 1. Physico-chemical characteristics of Gantrez ${ }^{\circledR}$ nanoparticles. Data were represented by mean \pm SD $(n=10)$.

\begin{tabular}{|c|c|c|c|c|c|}
\hline Formulations $^{(\mathbf{a})}$ & $\begin{array}{c}\text { LPS } \\
\text { content } \\
(\mu \mathrm{g} / \mathrm{mg})\end{array}$ & $\begin{array}{c}\text { OVA } \\
\text { content } \\
(\mu \mathrm{g} / \mathrm{mg})\end{array}$ & $\begin{array}{c}\text { Encapsulation } \\
\text { efficiency } \\
(\%)\end{array}$ & $\begin{array}{l}\text { Size } \\
(\mathbf{n m})\end{array}$ & $\begin{array}{c}\text { Zeta } \\
\text { Potential } \\
(\mathrm{mV})\end{array}$ \\
\hline NP & - & - & - & $158 \pm 3$ & $-45.1 \pm 0.5$ \\
\hline $\mathrm{OVA}^{\text {in }}-\mathrm{NP}$ & - & $30.1 \pm 4.5$ & $42.1 \pm 6.3$ & $239 \pm 4$ & $-50.8 \pm 2.9$ \\
\hline OVA $^{\text {in }}-$ LPS $^{\text {out }}$-NP & $15.2 \pm 0.5$ & $24.1 \pm 5.4$ & $33.9 \pm 7.6$ & $231 \pm 3$ & $-46.1 \pm 3.1$ \\
\hline $\mathrm{OVA}^{\text {in }}-\mathrm{LPS}^{\mathrm{in}}-\mathrm{NP}$ & $13.8 \pm 3.0$ & $26.5 \pm 0.3$ & $37.3 \pm 0.4$ & $227 \pm 4$ & $-34.1 \pm 3.4$ \\
\hline
\end{tabular}

${ }^{\text {(a) Formulations: NP: empty nanoparticles; } \text { OVA }^{\text {in }} \text {-LPS }}{ }^{\text {out }}$-NP: OVA-coated and LPSentrapped nanoparticles; OVA ${ }^{\text {in }}$-NP: OVA-entrapped nanoparticles; OVA ${ }^{\text {in }}$-LPS $^{\text {out }}$-NP: OVA-entrapped and LPS-coated nanoparticles; OVA ${ }^{\text {in }}$-LPS ${ }^{\text {in }}$-NP: OVA and LPSentrapped nanoparticles. 
Table 2. Anaphylactic symptoms in the treated vs. non-treated OVA allergic mice.

\begin{tabular}{|c|c|c|c|c|c|}
\hline $\begin{array}{c}\text { Immunotherapeutic } \\
\text { treatment }^{(\mathbf{a})}\end{array}$ & $\begin{array}{c}\text { Temperature } \\
\text { decrease }\left({ }^{\mathbf{}} \mathbf{C}\right)\end{array}$ & Piloerection & Mobility & Cyanosis & $\begin{array}{c}\text { Mortality } \\
\text { rate (\%) }\end{array}$ \\
\hline OVA-Alum & $3.62 \pm 1.03$ & ++ & Low & ++ & 80 \\
\hline PBS & $3.54 \pm 3.14$ & +++ & Low & +++ & 60 \\
\hline OVA $^{\text {in }}$-NP & $2.96 \pm 1.42$ & + & Low & + & 40 \\
\hline OVA $^{\text {in }}$-LPS & & & & \\
\hline OVA $^{\text {in }}$-LPS & & & & & \\
\end{tabular}

Severity of the symptoms: (-) absent; (+) weak; (++) moderate and (+++) strong.

(a) Treatments: OVA-Alum: OVA adsorbed to aluminium hydroxide; PBS: Phosphate buffer saline; OVA ${ }^{\text {in }}$-NP: OVA-entrapped nanoparticles; OVA ${ }^{\text {in }}$-LPS ${ }^{\text {out }}$-NP: OVAentrapped and LPS-coated nanoparticles; OVA $^{\text {in }}$-LPS $^{\text {in }}$-NP: OVA and LPS-entrapped nanoparticles. 
CHALLENGE (1 mg OVA i.p.)

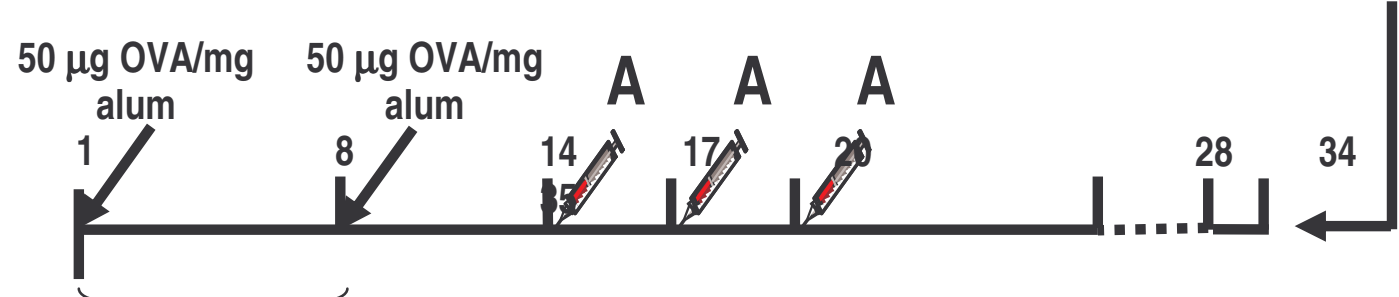

Sensitization

Figure 1 

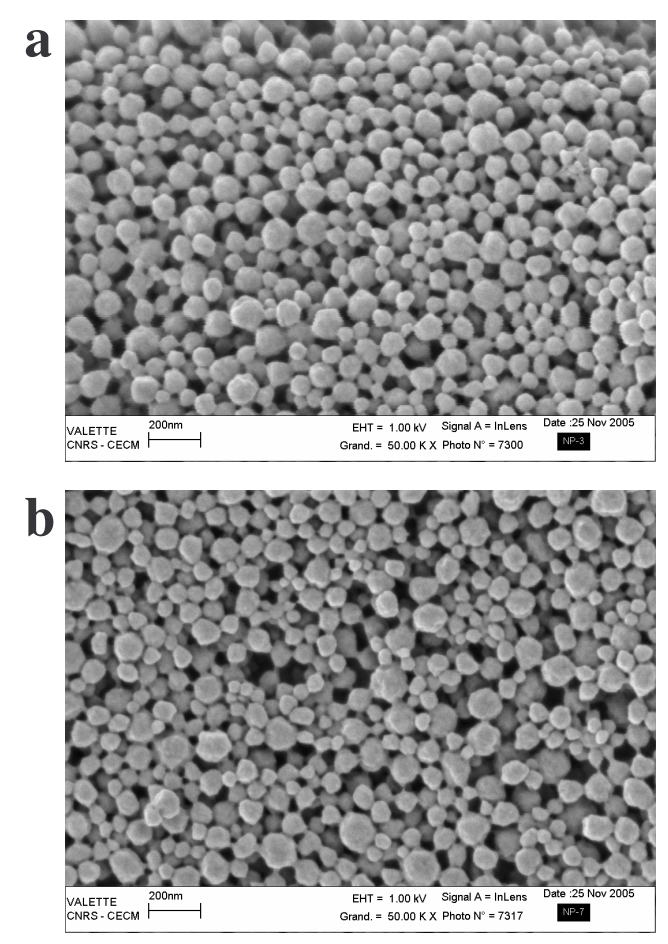

Figure 2 

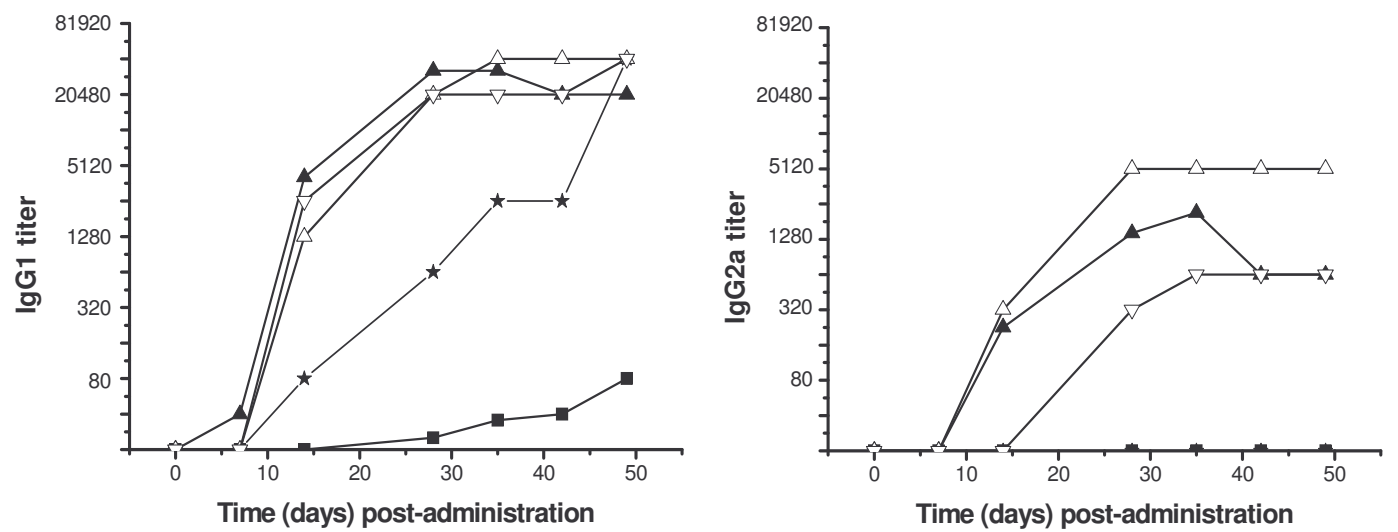

Figure 3 


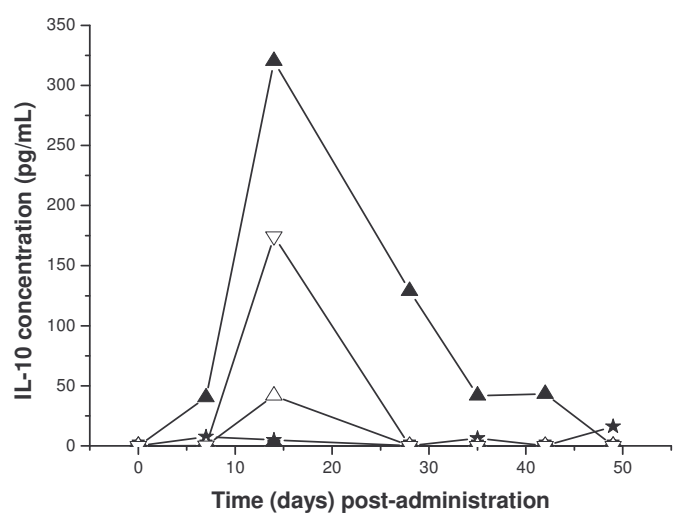

Figure 4 


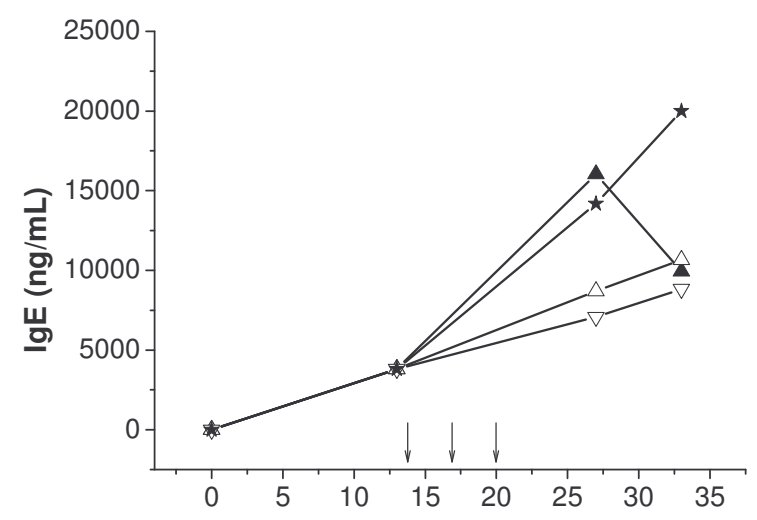

Figure 5 


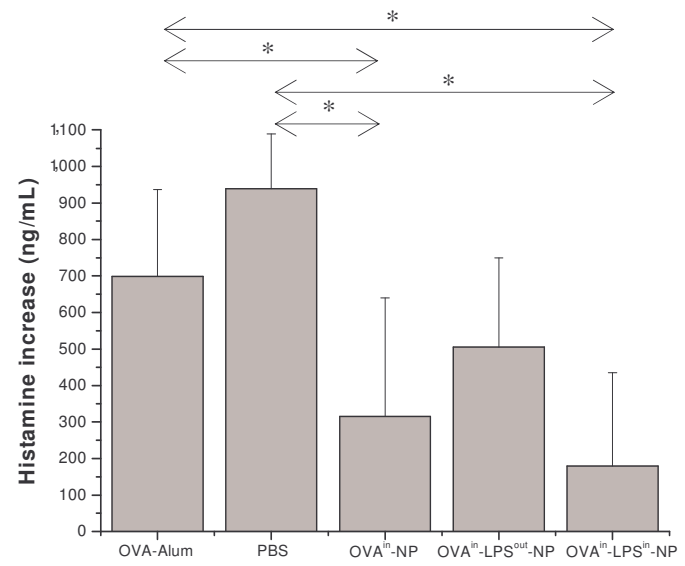

Figure 6 